San Jose State University

SJSU ScholarWorks

Master's Theses

Master's Theses and Graduate Research

1989

\title{
The Relationship of eating attitudes to depression, self-esteem and obsessional traits
}

Deborah A. Vitullo

San Jose State University

Follow this and additional works at: https://scholarworks.sjsu.edu/etd_theses

\section{Recommended Citation}

Vitullo, Deborah A., "The Relationship of eating attitudes to depression, self-esteem and obsessional traits" (1989). Master's Theses. 3116.

DOI: https://doi.org/10.31979/etd.scfg-dv6c

https://scholarworks.sjsu.edu/etd_theses/3116

This Thesis is brought to you for free and open access by the Master's Theses and Graduate Research at SJSU ScholarWorks. It has been accepted for inclusion in Master's Theses by an authorized administrator of SJSU ScholarWorks. For more information, please contact scholarworks@sjsu.edu. 


\section{INFORMATION TO USERS}

The most advanced technology has been used to photograph and reproduce this manuscript from the microfilm master. UMI films the text directly from the original or copy submitted. Thus, some thesis and dissertation copies are in typewriter face, while others may be from any type of computer printer.

The quality of this reproduction is dependent upon the quality of the copy submitted. Broken or indistinct print, colored or poor quality illustrations and photographs, print bleedthrough, substandard margins, and improper alignment can adversely affect reproduction.

In the unlikely event that the author did not send UMI a complete manuscript and there are missing pages, these will be noted. Also, if unauthorized copyright material had to be removed, a note will indicate the deletion.

Oversize materials (e.g., maps, drawings, charts) are reproduced by sectioning the original, beginning at the upper left-hand corner and continuing from left to right in equal sections with small overlaps. Each original is also photographed in one exposure and is included in reduced form at the back of the book. These are also available as one exposure on a standard $35 \mathrm{~mm}$ slide or as a $17^{\prime \prime} \times 23^{\prime \prime}$ black and white photographic print for an additional charge.

Photographs included in the original manuscript have been reproduced xerographically in this copy. Higher quality $6^{\prime \prime} \times 9^{\prime \prime}$ black and white photographic prints are available for any photographs or illustrations appearing in this copy for an additional charge. Contact UMI directly to order.

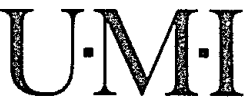




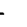


Order Number 1397850

The relationship of eating attitudes to depression, self-esteem and obsessional traits

Vitullo, Deborah Ánn, M.A.

San Jose State University, 1989

$\mathbb{U} \cdot \mathbb{M} \cdot \mathbb{I}$

300 N. Zeeb Rd.

Ann Arbor, MI 48106 

THE RELATIONSHIP OF EATING ATTITUDES TO DEPRESSION, SELF-ESTEEM AND OBSESSIONAL TRAITS

\author{
A Thesis \\ Presented to \\ The Faculty of the Department of Psychology \\ San Jose State University
}

In Partial Fulfillment

of the Requirements for the Degree

Master of Arts

by

Deborah A. Vitullo

May, 1989 
APPROVED FOR THE DEPARTMENT OF PSYCHOLOGY

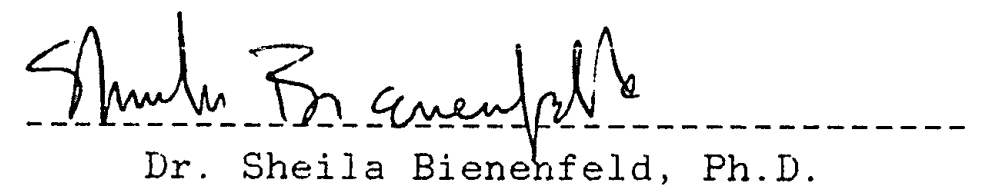
Dr. Sheila Bienehfeld, Ph.D.

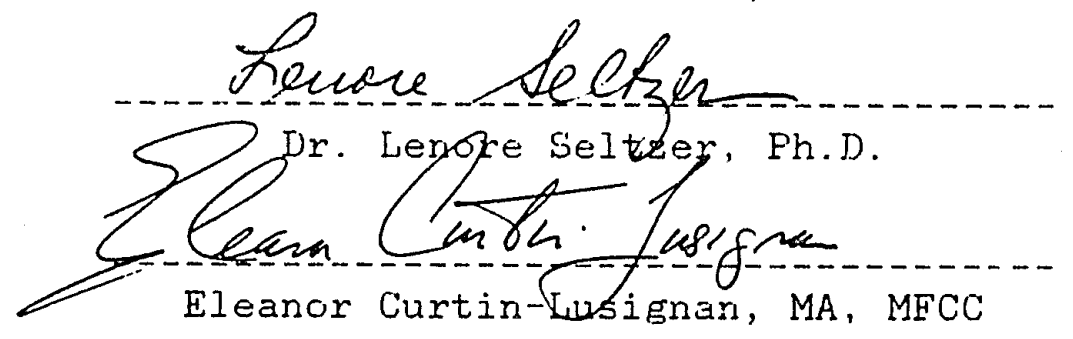

Eleanor Curtin-Lusignan, MA, MFCC

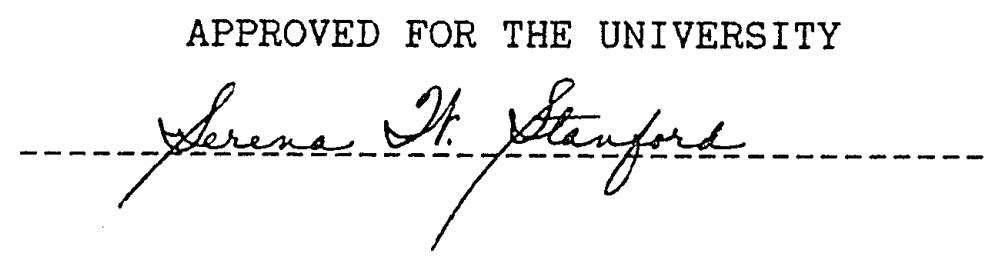


TABLE OF CONTENTS

CHAFTER

PAGE

I

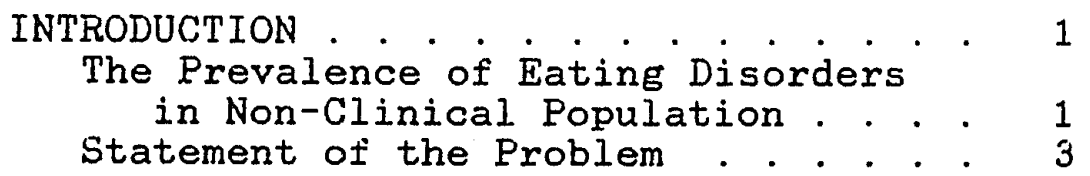

II

REVIEW OF RELATED LITERATURE . . . . . . 7

Depression . . . . . . . . . . . . . 7

Obsessive-Compulsive Neurosis. . . 8

Self-Esteem and Sense of

Erfectiveness . . . . . . . . . . y

Drug and Alcohol Abuse . . . . . . . . . 9

Dieting History . . . . . . . . . . . 10

III METHOD . . . . . . . . . . . . . . . 11

Subjects . . . . . . . . . . . . . . 11

Measures . . . . . . . . . . . . . 11

Design and Frocedure . . . . . . . 13

IV KESULTS AND DISCUSSION . . . . . . . 14

V SUMMARY . . . . . . . . . . . . . 20

REFERENCES . . . . . . . . . . . . . . . . . . 25

APPENDICES . . . . . . . . . . . . . . . . . . . . 31

Appendix A. Beck Depression Inventory . . . . . 31

Appendix B. Obsessive-Compulsive Scale . . . . . 34

Appendix C. Index of Self Esteem . . . . . . . 35

Appendix D. Eating Attitudes Test . . . . . . . 37

Appendix E. Dieting and Alcohol/Drug

History Questionnaire . . . . 39 


\section{LIST OF TABLES}

TABLE

PAGE

1. Mean Scores for EAT, BDI, ISE, OCS, Dieting History and Alcohol/Drug Abuse History

2. Fearsion Product-Moment \& Point-Biserial Correlation Coefficients Between EAT, BDI, OCS, ISE, Dieting History and $A / D$ History Scores

3. F Values for Differences Between Male and 18 Female Test Scores 
CHAPTER I

INTRODUCTION

\section{The Frevalence of Eating Disorders in}

NNon-CIInical Fopula

Anorexia nervosa is a syndrome characterized by extreme weight loss (Herzog \& Copeland, 1985), and disturbance of body image (Wingate \& Christie, 1978). Bulimia is a distinct syndrome which involves episodes of binge eating terminated by self-induced vomiting, the use of laxatives or diuretics, or restrictive dieting (Garfinkel, Moldofsky, \& Garner, 1980). Unlike anorexics, bulimics often maintain normal or near normal weight. Bulimic symptoms can occur in anorexia (Casper, Eckert, Halmi, Goldberg, \& Davis, 1980; Crisp, Hsu, Harding, \& Hartshorn, 1980), and many bulimics have a past history of anorexia (Fyle, Mitchell, \& Eckert, 1981). Eating disorders are seen predominantly in middle, or upper class white females (Garfinkel \& Garner, 1982). The prevalence of both disorders has doubled over the last two decades (Jones, Fox, Babigian, \& Hutton, 1980; Willi \& Grossman, 1983), and is now estimated to 
affect between 5 and $10 \%$ of adolescent girls and women in this country (Pope, Hudson, Yurgelun-Todd, \& Hudson, 1984).

Interest in the etiology and early diagnosis and treatment of eating disorders has led to investigations into the prevalience of these syndromes in non-clinical populations. Nylander (cited in Leon, Carrol1, Chernyk, \& Finn, 1985) found that $10 \%$ of 1,241 Swedish secondary school girls surveyed reported at least three anorexic symptoms in connection with weight loss, including fatigue, increased interest in food, depression, chilliness, poor school performance, constipation, anxiety, and amenorrhea. Hawkins and Clement (1980) found that $79 \%$ of female and $49 \%$ of male students questioned had binge episodes. In a similar study, $13 \%$ of students questioned (19\% of females, 5\% of males) reported havirg experienced all the major DSM-III symptoms for bulimia (Halmi, Falk, \& Schwartz, 1981).

Statement of the Problem

To date, a number of clinicians and researchers have noted several personality variables which seem to predominate in 
persons with eating disorders. These include depression (Cantwell, Sturzenberger, Burroughs, Salkin, \& Green, 1977; Eckert, Goldberg, Halmi, Casper, \& Davis, 1982; Katz, Kuperberg, Pollack, Walsh, Zummoff, \& Weiner, 1984; Russel1, 1979), low self-esteem (Baird \& Sights, 1986; Herzog \& Copeland, 1985; Wingate \& Christie, 1978) and obsessive-compulsive behaviors (Hecht, Fichter, \& Felicitas, 1983; Kron, Katz, Gorzynski, \& Weiner, 1978; Smart, Beumont, \& George, 1976). Additionally, it has been found that bulimics often report histories of alcohol and drug abuse, stealing, suicidal and self-destructive behaviors, lability of mood, and sexual promiscuity (Casper et al., 1980; Gartinkel et al., 1980; Stonehill \& Crisp, 1977). These findings have led some researchers to speculate that eating disorders are a variant of affective disorder (e.g., Brotman, Herzog, \& Woods, 1984). Others propose that they be classified as a subtype of obsessive-compulsive neurosis (Hecht et al., 1983). Hatsukami and associates (1982) reported two common MMPI codetypes for bulimics and speculated that there might be two subgroups of bulimics, one with a more obsessivecompulsive profile, and the other with addictive behaviors. 
Striegel-Moore and her associates (1986) argue against these "simple" classifications for eating disorders. They feel that the same factors that predispose an individual to drug abuse, would also predispose him/her to bulimia, namely, the inability to regulate negative feelings, the need for immediate gratification, poor impulse control, and a fragile sense of self. With regard to depression, they similarly point out:

At present, the question remains unanswered whether depression is a symptom secondary to bulimia, or whether a depressive syndrome places a woman at greater risk for bulimia ( $p .254$ ).

To address this question, the present study investigated the relationships between elevated scores on the Eating Attitudes Test (EAT) (Garner \& Gartinkel, 1979), which indicates a predisposition toward eating disorders, and above average scores on measures of depression, self-esteem and obsessive-compulsive symptomatology. Fositive significant correlations found between any measure and the EAT score were taken to indicate a personality profile for individuals at risk for developing eating disorders. The following hypotheses were developed: Hypothesis 1:

There will be a significant positive correlation between scores on measures of eating disorder attitudes and scores on measures of depression and obsessive-compulsive neurosis. 
Hypothesis ¿:

There will be a significant positive correlation between scores on the Eating Attitudes Test and scores on a self-esteem measure, where high scores indicate low self-esteem (thus indicating that self-esteem is negatively correlated with eating disorders).

Hypothesis 3:

There will be a significant positive correlation between Eating Attitudes Test scores and history of drug/alcohol abuse. Hypothesis 4:

Fersons scoring above average on the Eating Attitudes Test will also show a greater than average history of dieting and restrictive eating. 
CHAPTER 2

SURVEY OF RELATED LITERATURE

\section{Depression}

As noted previously, symptoms of depression are often seen in patients with ailorexia and bulimia. Cantwell et al. (1977) found a large percentage of anorexic patients manifested depressive symptomatology both before and after treatment. The results obtained by other investigators (e.g., Dally, 1969; Kay \& Leigh, 1954) support these findings.

Norman and Herzog (1983) subdivided their sample into restricting anorexics, bulimic anorexics, and normal-weight bulimics. Although the MMPI profiles of ali three groups correlated highly, some differences were noted. Iepression was the peak scale for all groups, with bulimics significantly more depressed than restricting anorexics. Other investigators have also found significantly high depression scores for anorexics and bulimics (Hatsukami et al., 1982; Herzog, 1984; Yates \& Sambrailo, 1984).

Depressive symptoms often increase during or after the binge/purge episode (Garner \& Garfinkel, 1979; Hawkins \& Clement, 1980). For some bulimic women, the binge/purge cycle serves a self-punishing purpose (Johnson, Lewis, \& Hagman, 1984) consistent with a depressive constellation (Striegel-Moore, Silberstein, \& Rodin, 1986). In a study of college students, in 
which $79 \%$ of the females and $49 \%$ of the males reported binge eating occurrences, 33 females reported that they "hated themselves" after a binge and 47 females reported becoming "moderately to very" depressed after binging (Hawkins \& Clement, 1980). No males reported these feelings. Binge eating in males correlated with external locus of control, whereas in females it correlated with low assertiveness and negative self-image. Obsessive-Compulsive_Neurosis

Hecht and associates (1983) found a large percentage of anorexic patients engaged in compulsive behaviors, such as compulsive washing and cleaning, compulsive checking rituals, compulsive exercise, and eating rituals. Kron et al. (1978) also noted obsessional walking and exercise in hyperactive anorexic patients. The importance of obsessional traits in individuals with eating disorders has also been stressed by other investigators (e.g., Smart et al., 1976). Throughout their book, Neuman and Halvorson (1983) stress the need for perfection in both anorexics and bulimics. They also note the compulsive nature of the binge-purge cycle itself and the similarity between bulimia and chemical dependency. Bulimia can be viewed as an obsessive fear of fatness combined with an addiction to food. In their study of anorexic and weight-preoccupied college and ballet students, Garner and associates (1983) also noted the elevated 
Ferfectionism Scale on the Eating Disorders Inventory (EDI) in weight-preoccupied women.

Self-Esteem and Sense of Effectiveness

A central issue for the anorexic is her overall sense of ineffectiveness and powerlessness within the family (Bruch, 1982). The anorexic's pursuit of thinness is seen as an effort to achieve some sense of control and self-esteem (Baird \& Sights, 1986; Herzog \& Copeland, 1985). Woods and Heretick (1983) found that anorexics scored significantly lower on measures of personal effectiveness and self-esteem than did normals. Anorexics also projected lower scores for themselves than were actually obtained. Baird and Sights (1986) also noted pervasive low selfesteem in both anorexic and bulimic clients. Anorexic patients have been found to have significantly lower ego-strength scores than normals (Wingate \& Christie, 1978). Low ego strength scores have been related to coping behavior and perceptions of reality. Such low scores for anorexics are consistent. with the body image distortion noted in this disorder (Wingate \& Christie, 1978). Drug and Alcohol Abuse

As noted previously, bulimics are more likely than normals to have histories of alcohol and drug abuse (Casper et al., 1980; Garfinkel et al., 1980; Stonehill \& Crisp, 1977). Pyle and 
associates (1983) found that bulimic students were more likely to have been treated for alcohol and drug problems and stealing behaviors than were non-bulimic students. Leon and associates (1985) found a significant relationship between family history of substance abuse problems and binging ( $43 \%$ of the bingers vs. $17 \%$ of the non-bingers). Among the bulimics in this study, $61 \%$ had histories of excessive alcohol use, and $46 \%$ had histories of drug use. In this group, 51\% also reported one or more first-degree relatives as having been diagnosed by health professionals as chemically dependent. Family history of chemical dependency was associated with more than two times greater risk for binging among college females, but did not substantially increase risk among college males.

Dieting History

Several researchers have proposed subclassifications of eating disorders, such as "subclinical anorexia" (Button \& Whitehouse, 1981) or "pursuit of thinness" (Lowenkopt, 1982), to include individuals who are abnormally preoccupied with weight. Evidence indicates that rigid dieting may, in fact, precipitate eating disorders in vulnerable individuals. Boskind-Lodahl and Sirlin (1977) found in each case of 100 women displaying bulimic symptoms, the woman's efforts to perfect herself through rigid 
dieting led to her first eating binge. Similarly, Hawkins and Clement (1980) found that the amount reportedly eaten during a binge significantly correlated with the binge precipitant of "going off a strict diet," which, in turn, was associated with depression and self-condemnation following the binge episode. Cultural pressures for thinness, especially on women, may, therefore, play an important role in the pathogenesis of anorexia nervosa and bulimia (Garner, Olmstead, \& Garfinkel, 1983). 
CHAPTER III

METHOD

\section{Sub.jects}

Subjects were 127 (50 male and 77 female) college students from classes at San Jose State University. Subjects were asked to voluntarily participate in this study by completing 5 short paper and pencil questionnaires. Test booklets were passed out by the professors, this investigator and student peers of several graduate and undergraduate classes within the Fsychology and Business departments to students who indicated an interest in participating in research on eating disorders. Subjects were required to sign a consent form before participating in this research. Subjects were permitted, if necessary, to take the test booklets home and return them to their professors when completed.

Measures

The Beck Depression Inventory (Beck, Ward, Mendelson, Mock, \& Erbaugh, 1961) was used to measure depression. This self-report measure contains 21 categories of symptoms and attitudes related to depression. Standard scoring procedures were used in 
this research (Steer, Beck, \& Garrison, 1986).

The Obsessive-Compulsive Scale (OCS) (Gibb, Bailey, Best, \& Lambirth, 1983) was used to assess obsessional symptoms and traits. This is a 20-item true-false questionnaire that measures a general tendency toward obsessive thoughts and compulsive behaviors. A score of 0 to 20 is possible, with higher scores indicating greater compulsivity.

The Index of Self-Esteem (ISE) (Hudson, 1982) was used to measure self-esteem. This is a 25 -item self-report test. On the ISE scores above 30 indicate a clinically significant problem, i.e., very low self-esteem.

The Eating Attitudes Test (EAT) was used to measure symptoms of eating disorders. This 40 -item scale is presented in a 6point forced choice, self-report format. Scores above 30 on this measure indicate disordered eating concerns (Corcoran \& Fischer, 1987 )

A short questionnaire, designed specifically for this study was also used. This questionnaire asked questions pertaining to dieting history and to past treatment for eating disorders, drug and/or alcohol abuse. 


\section{Lesign and Frocedure}

Mean scores for each test were calculated. The Fearson product-moment correlation was calculated between scores on the EAT and scores on the BDI, between scores on the EAT and scores on the OCS, between EAT and ISE scores, and finally between EAT scores and dieting history. The latter was measured by a 5-point Likert-type scale. Foint-biserial correlations were also determined between eating attitudes and history of treatment for drug and/or alcohol abuse. This history was scored as 0 for a negative response and 1 tor a positive response.

In addition to the overall statistics outlined above, separate analyses for male and for female subjects were performed. Analysis of variance ( $F$ test) was calculated to determine whether the differences in the male scores and the female scores were significant. 
CHAPTER IV

RESULTS AND DISCUSSION

The average scores for each test are shown in Table I. This table shows the overall average test score for each test taken, and also shows the breakdowns for male and female subjects for each measurement.

TABLE 1

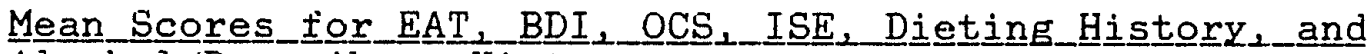
Alcohol $\angle$ D $\underline{\text { unE }}$ Abuse Hi

\begin{tabular}{lccccccr} 
& \multicolumn{1}{c}{ EAT } & BDI & OCS & ISE & DIET & A/D & AGE \\
OVERALL & 12.92 & 6.76 & 9.56 & 28.73 & 4.5 & 0 & 27.04 \\
FEMALE & 14.75 & 7.36 & 10.03 & 28.4 & 5.17 & 0 & 27.94 \\
MALE & 10.1 & 5.84 & 8.84 & 29.24 & 3.48 & 0 & 25.66
\end{tabular}

Three percent ( $3 \%$ ) of the subjects had clinically significant EAT test scores, indicating anorexic/bulimic behaviors. All of these subjects were female, indicating that approximately $8 \%$ of the females participating in this study were found to have either anorexia or bulimia (the EAT does not distinguish between these disorders). This finding is in agreement with that of Pope and associates, who estimate that 5 to $10 \%$ of adolescent girls and 
women in this country suffer from eating disorders (Fope et al., 1984). As was suggested in existing literature (Garfinkel \& Garner, 1982), none of the male subjects tested showed evidence of either disorder.

Of interest was the finding that $39 \%$ of the students tested scored 30 or higher on the Index of Self Esteem (39\% of the females and $38 \%$ of the males). It has been suggested (Hudson, 1982 ) that scores above $30( \pm 5)$ indicate that the respondent has a clinically significant problem with self-esteem (Hudson, 1982). According to these findings then, it would appear that problems of self-esteem are greater with college students than are eating disorders, although perhaps not as physically and emotionally detrimental. Similarly, 9 female subjects (12\%) and 1 male subject ( $2 \%$ ) displayed clinically significant Beck Depression Inventory scores. Correlation of Test Sconeres

Table II shows the correlation coefficients calculated between the various measures. 
TABLE II

Fearson Product-Moment and Point-Biserial Correlation Coefficents Between EAT, BDI, OCS, ISE, Dieting History and A/D History

Scores

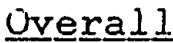

EAT BDI ISE DIET A A D

\begin{tabular}{|c|c|c|c|c|}
\hline EAT & $.43 *$ & $.331 *$ & $.291 *$ & $.454 *$ \\
\hline $\mathrm{BDI}$ & & $.522 *$ & $.731 *$ & \\
\hline OCS & & & $.301 *$ & \\
\hline
\end{tabular}

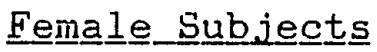

EAT

$\begin{array}{lllll}\text { BDI } & \text { OCS } & \text { ISE } & \text { DIET } & \text { A/D } \\ .452 * & .394 * & .333 * & .452 * & .013 \\ & .525 * & .786 * & \\ & & .367 * & \end{array}$

Ma_le_Subjects

\begin{tabular}{|c|c|c|c|c|c|c|}
\hline & EAT & $\mathrm{BDI}$ & OCS & ISE & DIET & $\mathrm{A} / \mathrm{D}$ \\
\hline EAT & & $.312 * *$ & .096 & $.320 * *$ & $.327 * *$ & -.076 \\
\hline $\mathrm{BDI}$ & & & $.513 *$ & $.645 *$ & & \\
\hline OCS & & & & .221 & & \\
\hline
\end{tabular}

$* \quad \underline{2}<.01$

$* * \mathrm{P}<.05$ 
As can be seen from Table II, significant correlations were found between nearly all pairs of tests. These correlations tended to be less strong for male subjects than for females. No significant correlations were found between EAT and OCS scores or between ISE and OCS scores for male subjects. These findings indicate that whereas the females tended to have more integrated personality profiles (at least with respect to these measures), the males did not. This may be to the male's advantage, since having a clinically significant problem in one area, e.g., eating attitudes, did not necessarily mean that the individual also had a problem in another, e.g., obsessive-compulsive behavior. Females, on the other hand, who had problems with depression, obsessive-compulsive behavior or self-esteem also tended to have disordered eating attitudes and vice-versa. These findings may explain the high incidence of eating disorders among women as compared to men.

Contrary to what was predicted, none of the groups tested showed a significant correlation between alcohol/drug history and eating disorders. This finding may relate to the fact that a college student population was used, but is more likely due to the small number of subjects who indicated past treatment for alcohol/drug abuse (only 8 subjects overall). In order to more clearly assess this factor, a similar study done with subjects 
who have histories or present problems with alcohol/drug abuse should be done.

As was predicted, there was a strong correlation between history of dieting and EAT scores $(\underline{\underline{r}}=.454, \underline{\mathrm{e}}<.01)$. This correlation was strongex for female $(\underline{r}=.452, \underline{p}<.01)$ as compared to male subjects $(\underline{r}=.327, \underline{p}<.05)$. These findings support the contention of several researchers that eating disorders are linked to rigid dieting behavior (Boskind-Lodahl \& Sirlin, 1977; Hawkins \& Clement, 1980).

Finally, Table III shows the $\underline{F}$ ratios calculated to determine significance differences in the test scores between female and male subjects.

TABLE III

E Value $\underline{\text { Ves_For }}$ Differences_Between Male F RATIO

EAT $12.176 *$

BDI

1.723

OCS

1.405

ISE

.085

DIET

$11.706 *$

$$
*=\mathrm{p}<.01
$$


As can be seen from Table III, only EAT scores and scores measuring history of dieting show a significant difference between female and male subjects. These findings suggest again that cultural pressure on women for thinness leads women to diet to a far greater extent than men. This dieting behavior may, in turn, precipitate eating disorders in certain women (BoskindLodahl \& Sirlin, 1977; Hawkins \& Clement, 1980). 
CHAPTER IV

\section{SUMMARY \& CONCLUSIONS}

The increasing prevalence of anorexia nervosa and bulimia over the last several decades had lead to a growing interest in the etiology of these disorders (Jones et al., 1980; Willi \& Grossman, 1983). Several personality variables, as well as a history of preoccupation with dieting as a means of weight control, have been linked to eating disorders.

Results of this investigation found that $8 \%$ of the nomen studied had anorexia nervosa and/or bulimia. Although this figure should cause some alarm, it is lower than those found for both depression and self-esteem. More females (12\%) than males (2\%) were clinically depressed. Clinically significant problems with self-esteem were found among $39 \%$ of women and $38 \%$ of the men.

Correlations between a measure of eating disorders (EAT) and various other personality measures were calculated. Significant correlations were found between each of the measures, with the exception of a history of alcohol/drug abuse. In other words, high test scores on the EAT (indicating greater tendency towards these disorders) were indicative of higher levels of depression, obsessive-compulsive neurosis, and low self-esteem (and vice versa). Similarly, high test scores for depression (as measured 
by the BDI) were correlated with high measures of obsessivecompulsive neurosis and low self-esteem and vice versa. These relationships, for the most part, remained consistent when results for male and female subjects were analyzed separately.

The overwhelming correlation among test scores seems to indicate that persons who are suffering from neurosis of a particular type are more likely to suffer from other neurosis, of any kind. Viewed in these terms, it becomes unclear whether previous observations regarding the depressive symptomatology in eating disorders (e.g., Cantwell et al., 1977, Dally, 1969; Kay \& Leigh, 1954) are indicative of a link between the two disorders or whether this linkage is a result of a "totality of personality" effect. The same question remains for obsessivecompulsive and low self-esteem traits. Further research needs to be done to assess both similarities and, more importantly, differences, between these disorders before any conclusions can be drawn about whether eating disorders are a variant of any of these other disorders.

A consistent finding, one that appears to be more meaningful, was the strong correlation between dieting behaviors (as measured by the frequency of dieting and weight loss/gain) and EAT scores $(\underline{r}=.454 / \underline{p}<.05, \underline{x}=.452 / \underline{p}<.05, \underline{r}=.327 / \underline{Q}<.01$ for total, female and male subjects respectively). These findings support those 
of previous investigatozs who have noted that rigid dieting may precipitate eating disorders in vulnerable individuals (BoskindLodahl \& Sirlin, 1977; Hawkins \& Clement, 1980). Viewed in conjunction with this finding, it may be appropriate to conclude that persons, especially women, who are depressed, and/or obsessively-compulsively inclined, and/or low in self-esteem may be more vulnerable to developing eating disorders when engaged in strict dieting behavior. Conversely, it may be these women who are more likely to diet to the extreme.

Contrary to prediction, no correlation was found between history of alcohol/drug abuse and eating disorders. No conclusion, however, can be drawn from this finding, as the number of subjects in this sample with alcohol/drug histories was very small.

Summary

In summary, this study found that $8 \%$ of the women tested had symptoms of an eating disorder. No male subjects were found to have this disorder. Although significant correlations were found between measures of eating disorders (EAT), depression (BDI), obsessive-compulsiveness (OCS) and low self-esteem (ISE), no conclusions regarding the etiology of eating disorders were drawn. Rather, it appears that these personality traits may 
distinguish persons who are more vulnerable to developing eating disorders.

A strong correlation between dieting and eating disorders (as measured by the EAT) was found ( $\underline{r}=.454, \underline{p}<.01)$. Additionally, a significant difference was found between female and male subjects on dieting history $(\underline{F}=11.706, \underline{p}<.01)$, indicating that women are far more likely to engage in dieting behaviors and thinking. The fact that the only significant differences in scores between male and female subjects were in both EAT scores and dieting seems to indicate that dieting plays a greater role in the etiology of eating disorders than do the other personality traits tested. Frevious investigation also supports this link. For example, Pyle and associaties found that, of 34 bulimic women interviewed, 30 reported a period of dieting just prior to the onset of bulimia (Pyle et al., 1981). Similarly, Boskind-Lodahl and Sirlin (1977) found that almost all of the 100 bulimics interviewed showed dieting preceding bulimia. Most compellingly, Keys and his colleagues (Keys, Brozek, Henschel, Mickelsen, \& Taylor, 1950) were able to induce binge eating in a group of normal-weight men by putting them on a reduced calorie diet until they were only $74 \%$ of their initial weight. 
These studies indicate that a new attitude toward dieting may need to be taken. Women, and men, must be educated about the possible dangers of restrictive dieting. More importantly, a greater acceptance of our bodies as they are is indicated. Perhaps it is dieting, and not bulimia or anorexia, that is the disorder to be treated. 
REFERENCES 
Baird, P., \& Sights, J.R. (1986). Low self-esteem as a treatment issue in the psychotherapy of anorexia and bulimia. Journal of Counseling and Development, $\underline{64}, 449-451$.

Beck, A.T., Ward, C.H., Mendelson, M., Hock. J., \& Erbaugh J. (1961). An inventory for measuring depression. Archives of General Psychiatry, 4 , 561-571.

Boskind-Lodahl, M., \& Sirlin, J. (1977, March). The gorgingpurging syndrome. Psychology Today, 50-52, 82-85.

Brotman, A.W., Herzog, D.B., \& Woods, S.W. (1984).

Antidepressant treatment of bulimia: The relationship between bingeing and depressive symptomatology, Journal of Clinical Psychiatry, $\underline{45}, 7-9$.

Bruch, H. (1982). Anorexia nervosa: Therapy and theory. American Journal of Psychiatry, 139, 1531-1538.

Button, E.J., \& Whitehouse, A. (1981). Subclinical anorexia nervosa. Psychological Medicine, 11, 509-516.

Cantwell, D.P., Sturzenberger, S., Burroughs, J., Salkin, B., \& Green, J.K. (1977). Anorexia nervosa: An affective disorder? Archives_of General Psychiatry, 34, 1087-1093.

Casper, R.C., Eckert, E.D., Halmi, K.A., Goldberg, S.C., \& Davis, J.M. (1980). Bulimia: Its incidence and clinical importance in patients with anorexia nervosa. Archives of General Psychiatry, 37, 1030-1035.

Corcoran, K. \& Fischer, J. (1987). Measures for clinical practice: A sourcebook. New York: The Free Press.

Crisp, A.H., Hsu, L.K.G., Harding, B., \& Hartshorn, J. (1980). Clinical features of anorexia nervosa. Journal of Psychosomatic Research, 24, $179-191$.

Dally, P. (1969). Anorexia nervosa. London: William Heinemann Medical Books.

Eckert, E.D., Goldberg, S.C., Halmi, K.A., Casper, R.C., \& Davis, J.M. (1982). Depression in anorexia nervosa. Psychological Medicine, 12, 115-122. 
Garfinkel, P.E., \& Garner, D.M. (1982). Anorexia_nervosa:_A multidimensional perspective. New York: Brunner-Mazel.

Garfinkel, P.E., Moldofsky, H., \& Garner, D.M. (1980). The heterogeneity of anorexia nervosa: Bulimia as a distinct subgroup. Archives of General Psychiattry, 37, 1036-1040.

Garner, D.M., \& Garfinkel, P.E. (1979). The Eating Attitudes Test: An index of the symptoms of anorexia nervosa. Psychological Medicine, 9 , 273-279.

Garner, D.M., Olmsted, M.P., \& Garfinkel, P.E. (1983). Does anorexia nervosa occur on a continuum?: Subgroups of weight preoccupied women and their relationship to anorexia nervosa. International Journal of Eating Disorders, 2, 11-20.

Gibb, G.D., Bailey, J.R., Best, R.H., \& Lambirth, T. (1983). The measurement of the obsessive-compulsive personality. Educational and Psychological Measurement, 43, 1233-1237.

Halmi, K.A., Falk, J.R., \& Schwartz, E. (1981). Binge-eating and vomiting: A survey of a college population. Psychological Medicinine, $\underline{9}, 273-279$.

Hatsukami, D.K., Owen, P., Pyle, R., \& Mitchell, J. (1982). Similarities and differences on the MMPI between women with bulimia and women with alcohol or drug abuse problems. Addictive Behavioxs, $7,435-439$.

Hawkins, R.C., \& Clement, P.F. (1980). Development and construct validity of a self-report measure of binge eating tendencies. Addictive Behaviors, $5,219-226$.

Hecht, H.M., Fichter, M., \& Felicitas, P. (1983). Obsessive-compulsive neurosis and anorexia nervosa. International Journal of Eating Disorders, $\underline{2}, 69-77$.

Herzog, D.B. (1984). Are anorexic and bulimic patients depressed? American Journal of Psychiatry, 141, 1594-1597.

Herzog, D.B., \& Copeland, P.M. (1985). Medical progress: Eating disorders. New England Journal of Medicine, 313, 295-303. 
Hudson, W.W. (1982). The clinical measurement package: A field mannuual. Chicago: Dorsey Press.

Johnson, C., Lewis, C., \& Hagman, J. (1984). The syndrome of bulimia. Psychiatric_Clinics of North America, 1, 247-274.

Jones, D.J., Fox, M.M., Babigian, H.M., \& Hutton, H.E. (1980). Epidemiology of anorexia nervosa in Monroe County, New York: 1960-1976. Psychosomatic Medicine, 42, 551-558.

Katz, J.L., Kuperberg, A., Pollack, C.P., Walsh, B.T., Zummoff, B., \& Weiner, H. (1984). Is there a relationship between eating disorder and affective disorder? New evidence from sleep recordings. American Journal of Psychiatry, 141, 753759 .

Kay, D., \& Leigh, D. (1954). The natural history, treatment and prognosis of anorexia nervosa, based on a study of 38 patients. Journal_of Mental_Science, 100, 411-431.

Keys, A., Brozek, J., Henschel, A., Mickelsen, O., \& Taylor, H. (1950). The biology of human starvation. Minneapolis:

University of Minnesota Press.

Kron, L., Katz, J.L., Gorzynski, G., \& Weiner, H. (1978). Hyperactivity in anorexia nervosa: A fundamental clinical feature. Comprehensive Psychiatry, 19, 433-440.

Leon, G.R., Carroll, K., Chernyk, B., \& Finn, S. (1985). Binge eating and associated habit patterns within college student and identified bulimic populations. International Journal of Eating_Disorders, $\underline{3}, 45-51$.

Lowenkopi, E.L. (1982). Anorexia nervosa: Some nosological considerations. Comprehensive Psychiatry, 23, 233-240.

Neuman, P.A., \& Halvorson, P.A. (1983). Anorexia nervosa and bulimia: A handbook for counselors and therapists. New York: Van Nostrand Reinhold Company Ine.

Norman, D.K., \& Herzog, D.B. (1983). Bulimia, anorexia nervosa, and ancrexia nervosa with bulimia: A comparative analysis of MMPI profiles. International Journal of Eating Disorders, 2 , 43-52. 
Pope, H.G., Hudson, J.I., Yurgelun-Todd, D. , \& Hudson, M.S. (1984). Prevalence of anorexia nervosa and bulimia in three student populations. International Journal of Eating Disorders $, \underline{3}, 45-51$.

Pyle, R.L., Mitchell, J.E., \& Eckert, E.D. (1981). Bulimia: A report of 34 cases. Journal of Clinical Psychiatry, 42 , 60-64.

Pyle, R.L., Mitchell, J.E., Eckert, E.D., Halvorson, P.A., Neuman, P.A., \& Goff, G.M. (1983). The incidence of bulimia in freshman college students. International_Journal of Eating_Disorders $\underline{\text { s. }}$, 75-85.

Russe11, G.F.M. (1979). Bulimia nervosa: An ominous variant of anorexia nervosa. Psychological Medicine, $\underline{\mathfrak{g}}, 429-448$.

Smart, D.E., Beumont, P.J.V., \& George, G.C.W. (1976). Some personality characteristics of patients with anorexia nervosa. British Journal of Psychiatry, 12으, 57-60.

Steer, R.A., Beck, A.T., \& Garrison, B. (1986). Applications of the Beck Depression Inventory. In N. Sartorius \& T.A. Ban (Eds.), Assessment of depression (Pp. 123-141). Heidelberg, Germany: Springer-Verlag Berlin.

Stonehill, E., \& Crisp, A.H. (1977). Psychoneurotic characteristics of patients with anorexia nervosa before and after treatment and at follow-up 4-7 years later. Journal of Fsychosomatic Research, 21, 187-193.

Striegel-Moore, R.H., Silberstein, L.R., \& Rodin, J. (1986). Toward an understanding of risk factors for bulimia. American Psychologist, 41, 246-263.

Willi, J., \& Grossman, S. (1983). Epidemiology of anorexia nervosa in a defined region of Switzerland. American Journal of Psychiatry, 140, 564-567.

Wingate, B.A., \& Christie, M.J. (1978). Egc strength and body image in anorexia nervosa. Journal of Psychomatic Research, 22, 201-204. 
Woods, W.P., \& Heretick, D.M. (1983). Self-schemata in anorexia and obesity. Imagination, Cognition and Personality, 3 , 3148 .

Yates, A.J., \& Sambrailo, F. (1984). Bulimia nervosa: A descriptive and therapeutic study. Behavioral Research and Therapy, 22, 503-517. 


\section{AGREEMENT TO PARTICIPATE IN RESEARCH AT SAN JOSE STATE UNIVERSITY}

RESPONSIBLE INVESTIGATOR: Deborah A. Syren-Vitullo

TITLE OF PROTOCOL: The Relationship of Eating Attitudes to Depression, Self-Esteem and Obsessional Traits

I have been asked to participate in a research study that is investigating the attitudes and feelings of college students on level of depression, self-esteem, obsessiveness and eating behaviors. The results of this study should further our understanding of the etiology of eating disorders in persons in this age group.

I understand that

1) I will be asked to read and answer all items on 5 short questionnaires. These questionnaires are in the form of multiple choice, True/False, and rating level of agreement with brief statements. The final questionnaire will ask me to answer several personal questions on my dieting history and on my history of drug or alcohol use, previous treatment for eating disorders and my age and gender. These questionnaires will take approximately 15 to 20 minutes to answer, although I know that I may take as long as I need to answer them all.

2) The possible risks of this study are that I may experience some discomfort in acknowledging some feelings or behaviors I may have.

3) The possible benefits of this study are that it will force me to think about feelings, behaviors and attitudes that are important in one's life and the knowledge that I may gain from this excercise. Also, I will have the positive feeling of knowing that this research may lead to a better understanding of the causes and possible treatment of eating disorders.

4) The results from this study may be published, but any information from this study that can be identified with me will remain confidential and will be disclosed only with my permission or as required by law.

5) Any questions about my participation in this study will be answered by Deborah Syren-Vitullo by calling (415) 651-6616. Complaints about the procedures may be presented to Dr. Kevin Jordan at (408) 924 -5625. For questions or complaints about research subject's rights, or in the event of research-related injury, contact Serena Stanford, $\mathrm{Ph} . \mathrm{D}$. (Associate Academic Vice President for Graduate Studies) at (408) 924-2480.

6) My consent is given voluntarily without being coerced; I may refuse to participate in this study or in any part of this study, and I may withdraw at any time, without prejudice to my relations with SJSU.

7 ) I have received a copy of this consent form for my file

I HAVE MADE A DECISION WHETHER OR NOT TO PARTICIPATE. MY SIGNATURE INDICATES THAT I HAVE READ THE INFORMATION PROVIDED ABOVE AND THAT I HAVE DECIDED TO PARTICIPATE. 


\section{PLEASE NOTE:}

Copyrighted materials in this document have not been filmed at the request of the author. They are avallable for consultation. however. in the author's university library.

These consist of pages:

$31-38$ 


\section{APPENDIX E}

Please answer the following questions as truthfully as you can.

1. How often are you dieting?

Never Rarely Sometimes Often Always

2. What is the maximun weight (in pounds) that you have ever lost in one month?

$\begin{array}{llll}0-4 & 5-9 & 10-14 & 15-19\end{array}$

3. What is the maximum weight gain within a week?
$0-1$
$1.1-2$
$2.1-3$
$3.1-5$
$5.1+$

4. Have you ever sought or received treatment and/or counseling for a drug and/or alcohol abuse problem.

$$
\text { No Yes }
$$

5. Have you ever sought or received treatment and/or counseling for an eating disorder?

No Yes

Please include the following information about yourself. This information is vital to the understanding of the results of this study. Your cooperation is greatly appreciated.

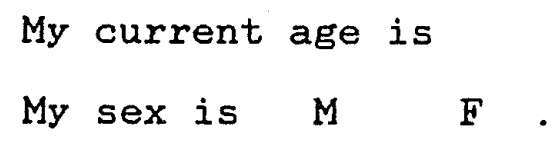

Thank you for your participation in this study. 